Article

\title{
From neural stem cells (NSC) to Glioblastoma (GBM): a natural history of GBM recapitulated in vitro
}

\author{
Cristina Almengló ${ }^{1,}$ Pilar Caamaño ${ }^{2}$, Máximo Fraga ${ }^{3}$, Jesús Devesa ${ }^{4}$, José A. Costoya ${ }^{*}{ }^{*}$, Víctor \\ M. Arce ${ }^{1 *}$ \\ 1 Molecular Oncology Laboratory MOL, Departamento de Fisioloxia, CiMUS, Faculta de de Me dicina, \\ Universida de de Santiago de Compostela, IDIS, Santiago de Compostela, Spain. \\ 2 Fundacion Publica Galega de Medicina Xenomica, Santiago de Compostela, Spain \\ 3 Departamento de Ana tomia Patoloxica e Ciencias Forenses, Universida de de Santiago de Compostela, \\ Santiago de Compostela, Spain \\ 4 Research and Development, Medical Center Foltra, Teo 15886, Spain \\ * Corre spondence: josea.costoya@usc.es; victor.arce@usc.es; Tel.: +34 881815449 (J.A.C.), +34 881815455 \\ (V.M.A.)
}

\begin{abstract}
Due to its aggressive and invasive nature glioblastoma (GBM), the most common and aggressive primary brain tumour in adults, remains almost invariably lethal. Significant advances in the last several years have elucidated much of the molecular and genetic complexities of GBM. However, GBM exhibits a vast genetic variation and a wide diversity of phenotypes that has complicated the development of effective therapeutic strategies. This complex pathogenesis makes it necessary the development of experimental models that could be used to further understand the disease, and also to provide a more realistic testing ground for potential therapies. In this report, we describe the process of transformation of primary mouse embryo astrocytes into immortalized cultures with neural stem cell characteristics, that are able to generate of GBM when injected in the brain of C57BL/6 mice, or heterotopic tumours when injected iv. Overall, our results show that oncogenic transformation is a fate for NSC if cultured for long periods in vitro. In addition, since no additional hit is necessary to induce the oncogenic transformation, our model may be used to investigate the pathogenesis of gliomagenesis and to test the effectiveness of different drugs throughout the natural history of GBM.
\end{abstract}

Keywords: Glioblastoma; neural stem cells; replicative senescence; metastasis

\section{Introduction}

Glioblastoma (GBM) is the most malignant and highly aggressive type of gliomas, which accounts for almost $50 \%$ of primary malignant brain tumours in adults. How ever, it still carries a poor prognosis, with a 5 -year survival of $4.7 \%$, due to its aggressive and invasive nature, and its remarkable heterogeneity [1-5]. These characteristics complicate the development of effective therapeutic strategies and compel the need for more trustw orthy models to study the disease and test new drugs and therapies.

In vitro cultures are widely employed as suitable models to investigate both the pathogenesis and the therapeutics of GBM, although these models are imperfect for several reasons. Different lines of immortalized glioma cells, such as U87, U251, T98G, or CT-2A have been widely used for more than 30 years [6-8]. How ever, although the use of cell lines has provided a valuable knowledge about GBM, they undergo profound phenoty pical changes when grown as monolayers, and fail to develop the defining morphological features of GBM tumours when injected in vivo. These cells also exhibit markedly different responses to cytotoxic treatments than those observed in patients, and controversy regarding their origins has recently appeared [8]. 
On the other side, the use of patient derived cells has become the gold standard of GBM preclinical studies, mainly to test personalized therapies, and a library of annotated and validated cell lines derived from surgical samples of GBM patients has been r ecently created [5,6]. It is expected that the use of validated cells, together with novel culture systems that better recapitulate the complex reality of brain tumours growing in situ [7] may provide a more suitable model for preclinical GBM research in the next future. How ever, despite their clear benefits over some current models, these models still have important limitations when investigating the pathogenesis of GBM, since they are established from already developed tumours, either spontaneously generated in a patient or experimentally induced in a cell line or laboratory animal. Therefore, it is very difficult to recapitulate the natural history of the oncogenic process and identify molecular targets involved in the early development of the disease.

In this study we describe a novel cellular model that allows to investigate the transformation of mouse neural stem cells (NSC) into aggressive GBM with metastatic capacity. Our results show that oncogenic transformation occurs in immortalized NSC because of long-term passaging in vitro, and without the need of any external hit. Furthermore, this transformation occurred with a $100 \%$ frequency, indicating that it is the fate of immortalized NSC in vitro, at least under our experimental conditions. Whether a similar process may occur in vivo, as a consequence of the dysregulation of the neurogenic niche, remains to be elucidated.

\section{Results}

\subsection{Generation of NSC with capacity to generate GBM in vivo}

In keeping with our previous report [9], both LP- and HP-immortalized cultures obtained from mouse embryo brains retain their capacity to express specific markers for all neural lineages (data not shown). Also in concordance with our previous findings, neurosphere formation can be induced by placing the cells under NBE conditions (data not shown). Altogether, these characteristics indicate that both types of cultures can be considered as bona fide immortalized NSC.

Table 1. Generation of GBM in mice after orthotopic injection of primary (1), LP-immortalized NSC (2) or HP-immortalized NSC (3) (see figure 7 for further details)

\begin{tabular}{|c|c|c|}
\hline Mice No. & Cell type (passages) & Time to tumour \\
\hline 1 & $1(-)$ & No tumour \\
\hline 2 & $1(-)$ & No tumour \\
\hline 3 & $2(15)$ & No tumour \\
\hline 4 & $2(15)$ & No tumour \\
\hline 5 & $3(40)$ & 3.5 months \\
\hline 6 & $3(40)$ & 3.5 months \\
\hline 7 & $3(40)$ & 3.5 months \\
\hline 8 & $3(60)$ & 3.5 months \\
\hline 9 & $3(60)$ & 3.5 months \\
\hline 10 & $3(60)$ & 3.5 months \\
\hline 11 & $3(90)$ & 3.5 months \\
\hline
\end{tabular}




\begin{tabular}{|c|c|c|}
\hline 12 & $3(90)$ & 3.5 months \\
\hline 13 & $3(90)$ & 3.5 months \\
\hline
\end{tabular}

In addition, we also reported that HP-immortalized NSC show a sharp increase in their proliferative rate, as compared with either primary or LP-immortalized cells, together with the presence of numeral chromosomal abnormalities [10]. Since these phenoty pical traits may indicate a potential for cellular transformation, in the present study, we first investigated their capacity to generate brain tumours in vivo. To this end, cell suspensions of either LP- or HP-immortalized NSC were injected into the cerebral parenchyma of C57BL/6 mice. As table 1 shows, development of orthotopic tumours was observed in all mice injected with HP-immortalized NSC (40, 60 or 90 passages), as soon as 3.5 months of injection (see also Fig. 1A). In contrast, no tumours were observed in mice injected with either primary cultures or LP (15 passages) immortalized cells. Tumours show ed many of the distinctive characteristics of GBM [2] including a marked cellular pleomor phism, and the presence regions of necrosis, together with extensive vascular hyperplasia, thrombus formation, invasion of vessel walls, and prominent Ki67 expression (Fig. 1B and 1C). Demonstration that tumours are not spontaneously generated but arise from the injected cells was obtaining by detecting the expression of RFP in the tumour cells (Fig. 1D). Finally, as occurs with immortalized NSC, cells isolated from GBM can growth as a monolayer cultures, that can be induced to form neurospheres by placing them in NBE conditions (Fig. 1E). Furthermore, GBM-derived cells also retain their capacity to express specific markers from all the three neural lineages (Fig. 1E and 1F), although a prominent decrease in GFAP expression exists.
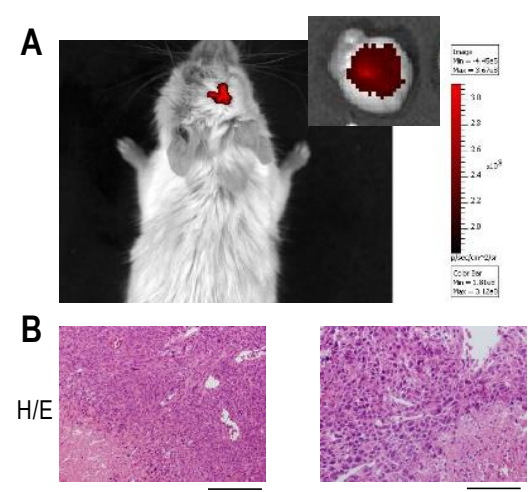

$50 \overline{\mu \mathrm{m}}$
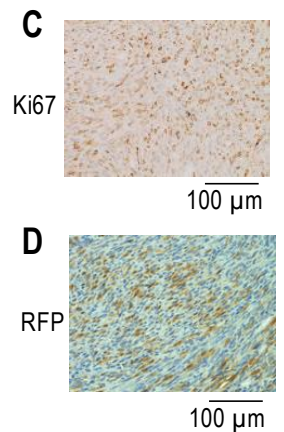
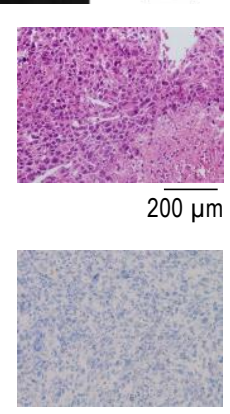

$\overline{100 \mu \mathrm{m}}$

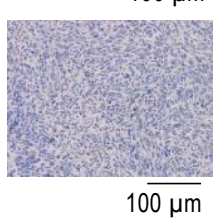

\section{E}

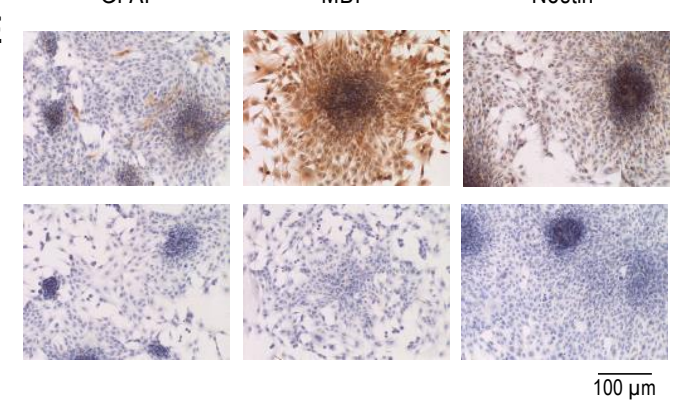

$\mathbf{F}$

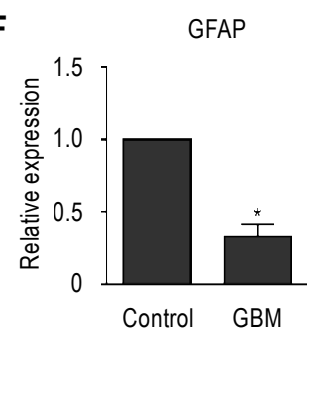

MBP

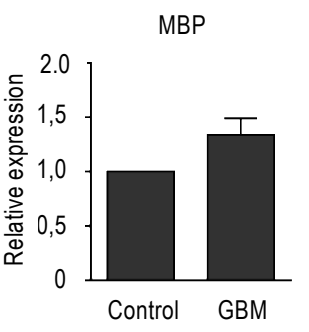

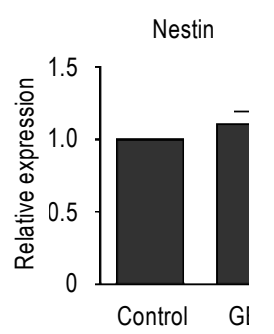

Figure 1. Generation of GBM in mice after orthotopic injection of HP-immortalized NSC. Cell suspensions of 3×105 cells obtained from primary cultures, LP-immortalized NSC (15 passages) or HP-immortalize d NSC (40, 60 or 90 passages) we re injected into the brain of C57BL/ 6 mice. (a) In vivo fluore scence imaging of one of the tumours generated 3.5 months after the injection. A more detailed image of the brain is shown in the insert. (b) Representative haematoxylin-eosin staining showing some of the pathological hallmarks of GBM, including the marked cellular pleomorphism, and the presence regions of extensive vascular hyperplasia, vascular invasion, and necrosis. (c) 
Immunohis tochemical de tection of Ki67 shows increa sed expression in GBM (left), as compared with controls (right). (d) Demonstration that GBM arise from injected cells was obtained by immunohistochemical detection of the RFP prote in (left), while no RFP expression was detected in controls (right). (e), (f). GBM-de rive d cells retain NSC characteristics. Tumours we re dissocia ted and cells were grown in DMEM (see materials and methods for further details). Neurosphere formation was induced by placing the cells in NBE conditions. Expression of specific lineage markers for astrocytes (GFAP), oligodendrocytes (MBP) and neurons (nestin) was detected by immunocytochemistry (e) (lower panels a re the negative controls) or by semi-quantita tive RT-PCR (f) (in this case, primary cells were used as control).

\subsection{Generation of NSC with capacity to generate heterotopic (metastatic) tumours in vivo}

One of the more intriguing aspects of the biology of GBM is their ability to form metastasis, most likely because of the notion that extracranial/extraspinal metastases of human GBM are clinically rare [11-14]. Therefore, we took advantage of our cellular model to investigate the ability of either HPimmortalized NSC or GBM-derived cells to form metastatic (heterotopic) tumours in vivo after injection in the tail vein of C57BL/6 mice. As table 2 shows, macroscopic lung tumours w ere observed in all mice injected with HP-immortalized NSC (4 mice) after 6 months of injection. In contrast, no tumours were detected after 3 or 4 months of injection of HP-immortalized NSC. In addition, a macroscopic lung tumour was also detected in one of three mice injected with GBM-derived cells, although, in this case, the tumour developed as soon as 3 months after injection (Table 2). Macroscopic examination of metastatic lungs showed the presence of single or multiple metastatic nodules with cannonball appearance and frequent haemorrhagic foci (Fig. 2A). Haematoxylin and eosin staining of the lung metastasis showed the existence of distinct characteristics of GBM-derived cells, including the presence of marked cellular pleomorphism and necrosis (Fig. 2B), together with the existence of prominent Ki67 expression (Fig. 2C). As in the case of primary brain tumours, demonstration that metastatic (heterotopic) tumours arise from injected cells was obtained by investigating the existence of RFP expression (Fig. 2D). Furthermore, cells isolated from metastatic tumours can grow th as monolayer cultures that can be induced to form neurospheres when placed in NBE conditions (Fig. 2E). As also occurs with GBM-derived cells, cells obtained from heterotopic tumours retained the expression of specific markers for all neural lineages (Fig. 2E and 2F).
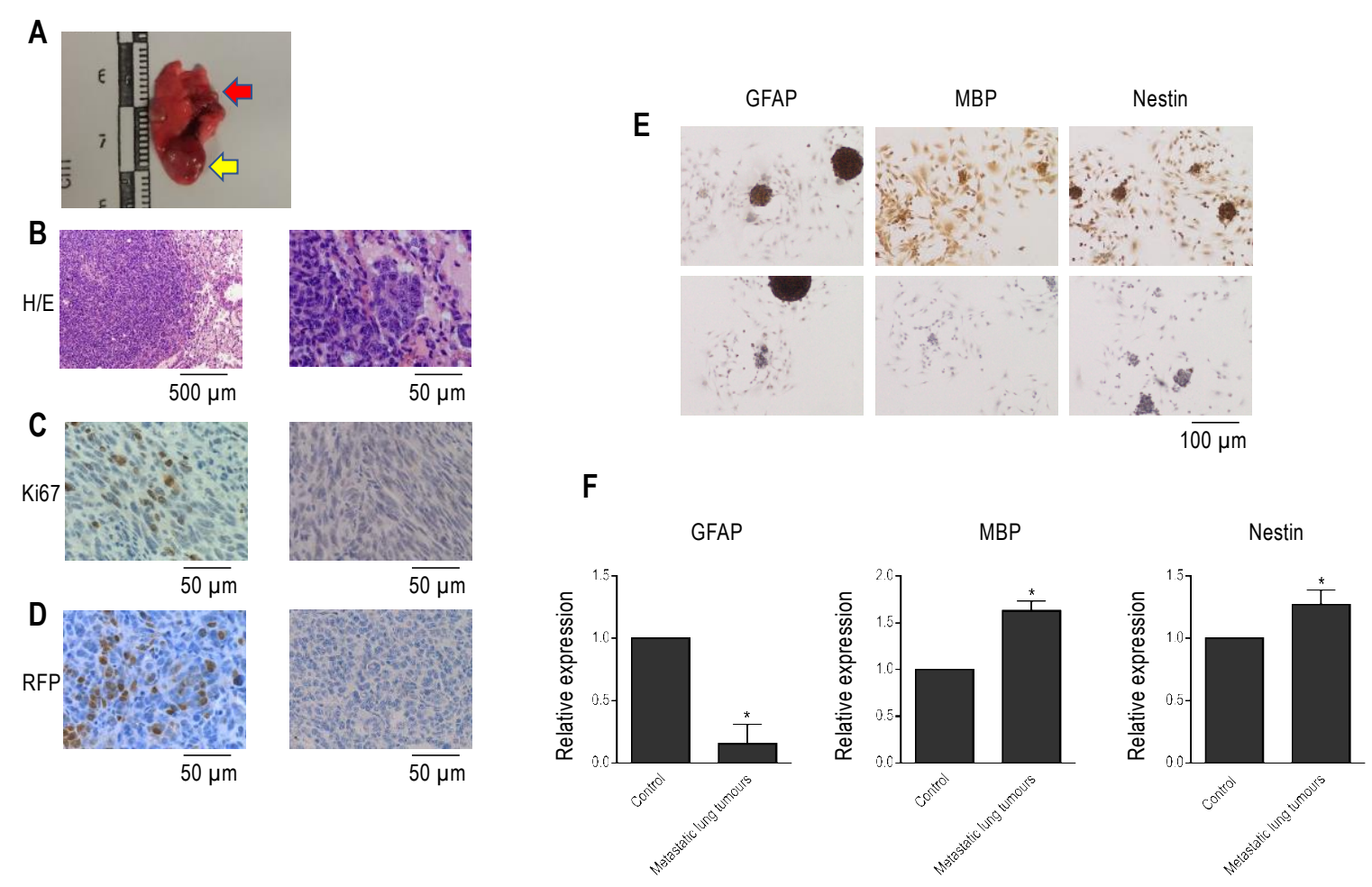
Figure 2. Characterization of metastatic (heterotopic) lung tumours. Cell suspensions of $3 \times 105$ cells obtaine d from HP-immortalized NSC (90 passages) or GBM-de rived cells we re injected in the tail vein C57BL/6 mice. (a) Macroscopic as pect of one representative metastatic lung. Notice the presence of cannonball-like tumours (yellow arrows), together with the existence of haemorrhagic areas (red arrows). (b) Haematoxylin-eosin staining reveals the presence of blood vessels surrounding the micro metastases in addition to the tumour's own vasculature. (c) Immunohistochemical de tection of Ki67 shows increased expression in the tumour (left), as compared with the control (right). (d) Demonstration that GBM a rise from injected cells was obtained by immunohistochemical detection of the RFP protein (left), while no RFP expression was detected in the control. (e), (f). Cells from lung metastatic tumours dis play NSC characteristics. Lung tumours were dissociated, and cells were grown in DMEM (see materials and methods for further details). Neurosphere formation was induced by placing the cells in NBE conditions. Expression of specific line a ge markers for astrocytes (GFAP), oligodendrocytes (MBP) and neurons (nestin) was de tected by immunocytochemistry in cells de rived from metastatic lung tumours (e). Lower panels are the negative controls. Notice the presence of neurospheres attached to the culture dish in all cases. Expression of specific lineage markers was also detected by semi-quantita tive RT-PCR (f) (in this case, primary cells were used as control).

Table 2. Generation of metastatic tumours in mice after iv injection of HP-immortalized NSC (cell type 3) or GBM-derived cells (cell type 4) (see figure 7 for further details). Asterisks denote the presence of microscopic tumours.

\begin{tabular}{|c|c|c|c|}
\hline Mice No. & Cell type (passages) & Time to tumour & Organ \\
\hline 1 & $3(40)$ & 4 months & No tumour \\
\hline 2 & $3(40)$ & 4 months & No tumour \\
\hline 3 & $3(40)$ & 6 months & Lung, kidney*, spleen* \\
\hline 4 & $3(40)$ & 6 months & Lung \\
\hline 5 & $3(60)$ & 4 months & No tumour \\
\hline 6 & $3(60)$ & 4 months & No tumour \\
\hline 7 & $3(60)$ & 4 months & No tumour \\
\hline 8 & $3(90)$ & 3 months & No tumour \\
\hline 9 & $3(90)$ & 4 months & No tumour \\
\hline 10 & $3(90)$ & 6 months & Lung, Kidney* \\
\hline 11 & $3(90)$ & 6 months & Lung, liver* \\
\hline 12 & 4 & 3 months & Lung*, liver* \\
\hline 13 & 4 & 3 months & Lung \\
\hline 14 & 4 & 3 months & Lung*, liver* \\
\hline
\end{tabular}

Despite the low rate of extracranial metastasis that exists in GBM, recent reports have described the existence of circulating tumour cells (CTC) in the peripheral blood of patients with GBM [13, 15]. Therefore, in order to further investigate the blood dissemination of injected cells, we performed cellular cultures of brain, lung, kidney, spleen, brain, bone marrow, testicles, and liver, obtained from mice injected with either HP-immortalized cells or GBM-derived cells. The presence of tumoral cells 
in these tissues, was demonstrated by growing primary cultures in DMEM, and inducing the formation of neurospheres by placing them in NBE conditions. Evidence of microscopic heterotopic tumours was found in kidney, liver and/or spleen in all but one mouse with macroscopic lung tumours induced by injection of HP-immortalized NSC (Table 2). Microscopic lung and liver metastasis were also observed in the tw o mice injected with GBM-derived cells that did not develop macroscopic tumours three months after injection (Table 2). Formation of neurospheres was not observed, in any case, in primary cultures from bone marrow, testicle, or brain. As expected, neurospheres expressed specific markers for all neural lineages. (Fig. 3).
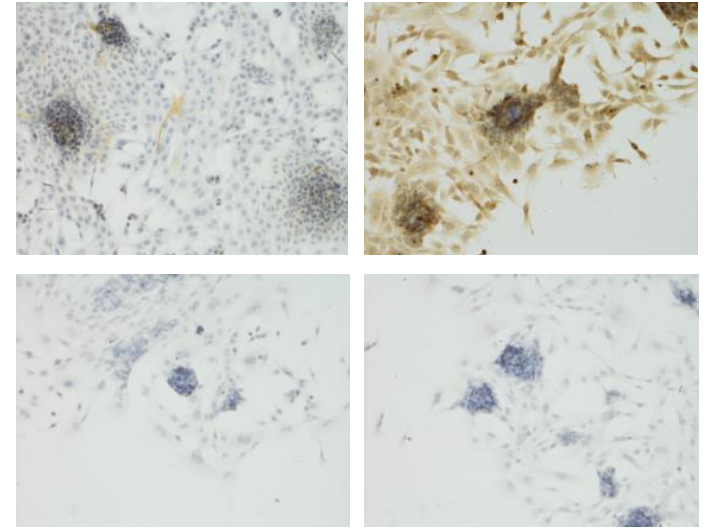
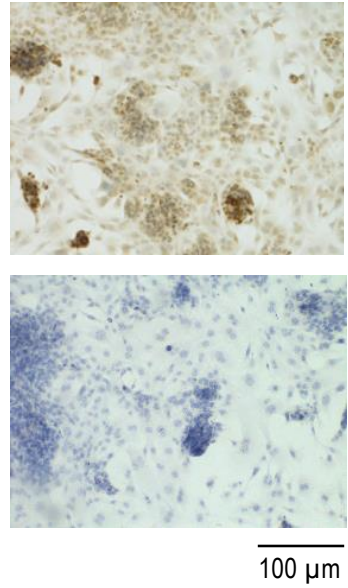

Figure 3. Identification of micros copic he terotopic tumours. Cell sus pensions of 3x105 cells obtained from HP-immorta lize d NSC (90 passages) or GBM-derived cells we re injected in the tail vein C57BL/6 mice and cell culture s from brain, lung, kidney, spleen, brain, bone marrow, te sticles, and liver were performed to investigate the presence of micrometastasis. In all cases, cells we re grown in DMEM (see materials and me thods for further de tails)., and neuros phere formation was induced by placing the cells in NBE conditions. Repre sentative image of a cell culture generated from liver is shown. The presence of neurospheres attached to the culture can be appreciated. Expression of specific lineage markers for astrocytes (GFAP), oligodendrocytes (MBP) and neurons (nestin) was detected by immunocytochemistry. Lower panels are the negative controls.

\subsection{Phenotypical characterization of immortalized, tumoral and metastatic NSC}

Altogether, our results demonstrate that continual passaging of cell cultures obtained from mouse embryobrain results in the generation of immortal cells with NSC characteristics that, finally, acquire the capacity to generate both primary GBM and heterotopic tumours in vivo. Therefore, to better understand the mechanisms underlying this transformation, we next investigated the presence of cellular aneuploidy, one of the hallmarks of the oncogenic process [16-18]. As figure 4 depicts, more than $80 \%$ of primary cells have 40 chromosomes, but a sharp increase in the number of numerical chromosome abnormalities is observed in immortalized cells, even in LP cells. This finding is in concordance with our previous reports [19] and indicates that hyperploidy is an early event within the transformation process of NSC. Although the percent of cells with severe polyploidy is greater in HP-immortalized or in tumoral (either primary or heterotopic) cells, the most striking changes occur soon after immortalization is achieved. 
A

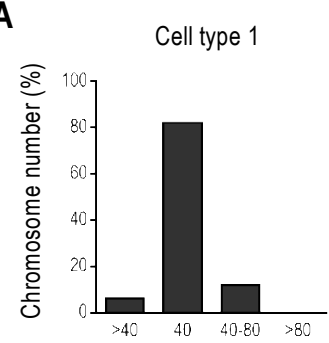

Cell type 3

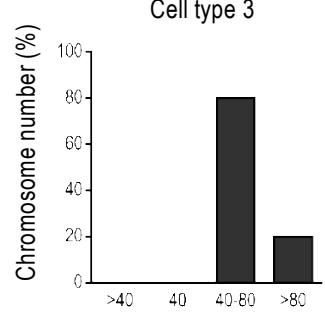

Cell type 5

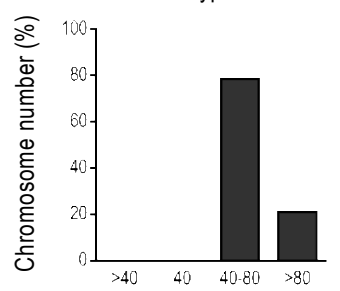

Cell type 2

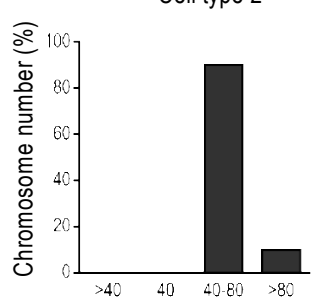

Cell type 4

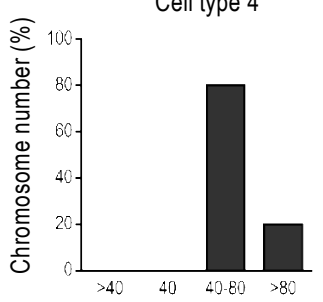

Cell type 6

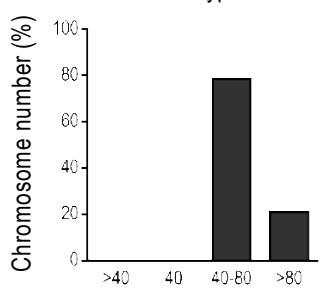

B

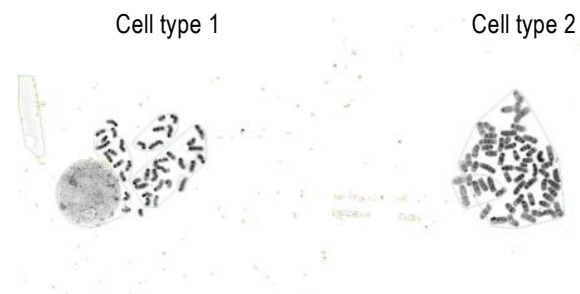

Cell type 3

Cell type 4

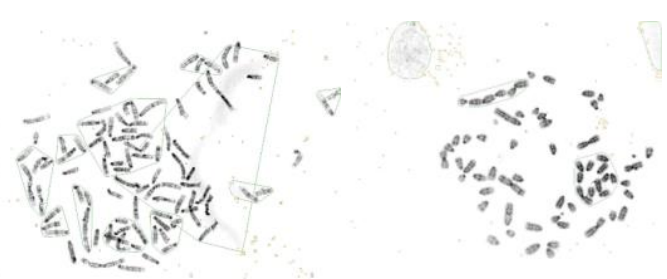

Cell type 5

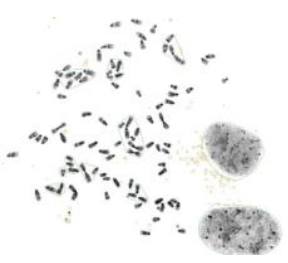

Cell type 6

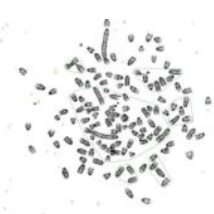

Figure 4. Changes in the amount of numerical chromosome abnormalities throughout the transformation process. Metaphase spreads were prepared from primary (cell type 1), LPimmortalized NSC (cell type 2), HP-immortalized NSC (cell type 3), GBM-derived cells (cell type 4) or metastasis-derived cells (cell types 5 and 6) cells. Cells were spotted onto microscope slides and stained with $2 \%$ W right in Gurr buffer ( $\mathrm{pH} 7.0$ ), and metaphase chromosomes we re scored using a Leica 2005 microscope under a 100X oil objective lens. (a) Distribution of chromosome number (\%) for each cell type, showing a dramatic increase in the number of hyperploid cells, already present in LP-immortalized NSC (cell type 2), as compared with primary cells (cell type 1). An increase in the number of highly hyperploid cells is also observed in HP-immortalized NSC (cell type 3), as well as in the other cell types. (b) Representative images of re sults presented in panel A.

These changes in cellular aneuploidy correlate with other phenotypical and biochemical modifications observed. When compared with primary cells, both LP- and HP-immortalized cells showed an increase in their proliferation rate(Fig. 5A and 5B), a finding that is also in keeping with our previous results [19]. Interestingly, the increase in grow th rate observed in HP-immortalized cells is similar to that observed in GBM-derived cells (Fig. 5A and 5B), and contact inhibition was preserved in both cases (data not shown). However, the highest proliferative rate was observed in cells obtained from heterotopic tumours, either generated from HP-immortalized cells or GBMderived cells (Fig. 5A and 5B). These differences in cell proliferation sharply correlate with the changes observed in the expression of $\mathrm{Ki} 67$ and in the rate of BrdU incorporation. In fact, whileless than $50 \%$ of either primary or LP-immortalized cells show immunoreactivity to Ki67, more than $90 \%$ of HP-immortalized or GBM-derived cells, and virtually all cells derived from heterotopic tumours are Ki67+ (Fig. 5C). In the case of BrdU incorporation, a significant increase was already observed in LP-immortalized cells when compared with control cells, but the most striking boost was found in HP-immortalized NSC. BrdU uptake remained similarly increased among all tumour-derived cell types, either primary or metastatic (Fig. 5D). Also in keeping with our previous findings, continual cell passaging resulted in the appearance of dramatic morphological changes. Although flat, polygonal cells were still present in hastily growing cells, most of them displayed distinct 
morphological modifications, including the presence of multinucleated cells with very large cytoplasms and long thin projections (data not shown).

\section{A}

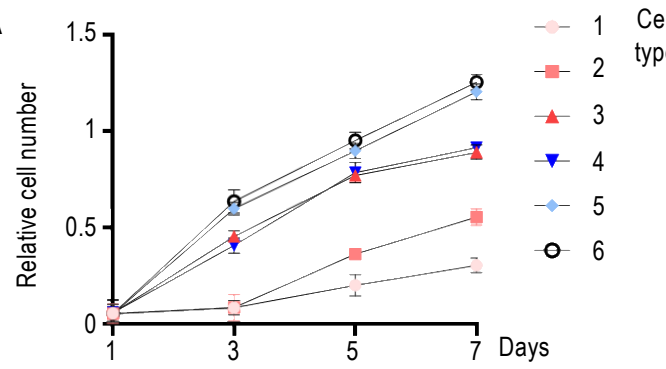

C

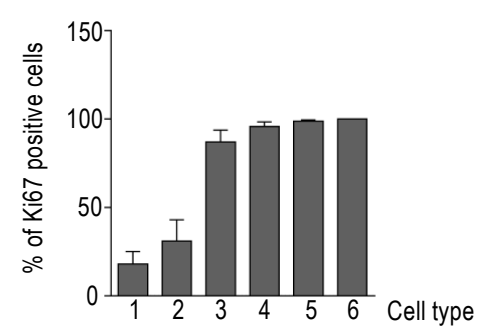

D

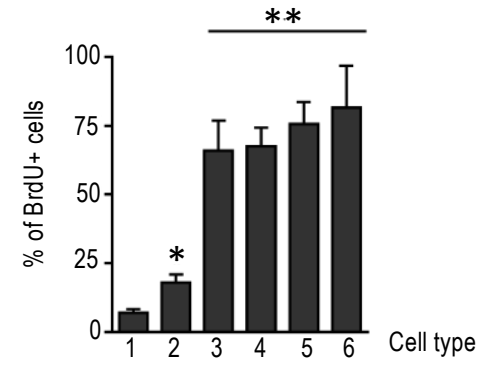

B

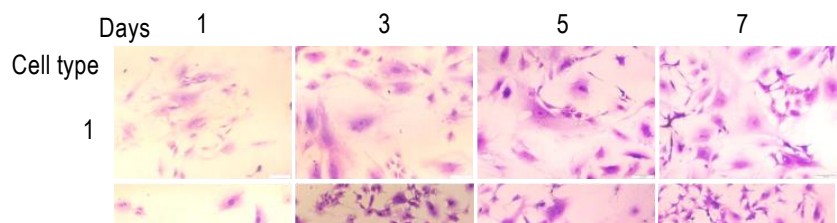

2

3

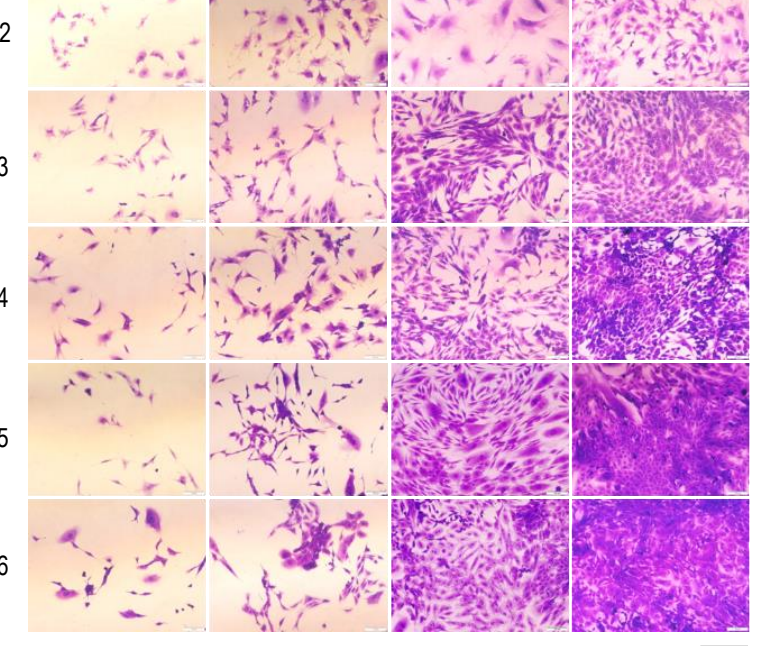

$\overline{100 \mu \mathrm{m}}$

Figure 5. Progressive increase in the rate of cell prolife ration throughout the transformation progress. (a) Primary (cell type 1), LP-immortalize d NSC (cell type 2), HP-immortalized NSC (cell type 3), GBMderived cells (cell type 4) or metastasis-derived cells (cell types 5 and 6) we re cultured, and cell number was determined by crystal-violet staining. A progressive increase in the growth rate was observed from 1 to 5-6. (b) Representative images of re sults presented in panel A. (c) Ki67 staining in the different cell types. The percent of Ki67+ cells was determined after scoring them by immunocytochemistry. (d) BrdU incorporation was determined by immunocytochemistry. In this case, each bar represents the mean+SEM of 3 experiments in triplica te ${ }^{*}=p<0.05$ vs primary cells.

\subsection{Biochemical characterization of immortalized, tumoral and metastatic NSC}

Finally, we investigated the biochemical changes underlying the timeline of the modifications that led to the transformation of primary cells into GBM-producing cells. Although GBM displays a heterogeneous profile, a common feature of all GBM types is an aberrant kinase signalling, and among the pathways implicated, the RAS-mitogen-activated protein kinase (MAPK), is one of the most frequently dysregulated in GBM cells [20-22]. In keeping with this, undetectable levels of either Raf-1 or ERK1 phosphorylation were observed in both primary cultures and LP-immortalized cells (Fig. 6), while a clear rise was detected in HP-immortalized cells. Furthermore, this activation w as progressively increasing throughout the transformation process, with the highest phosphorylation levels found in cells from heterotopic tumours. A similar pattern of activation was observed in the case the two leading members of the RSK (90 kDa ribosomal S6 kinase) family, RSK1 and RSK2, two downstream 
effectors of the ERK pathway [23] (Fig. 6). RSK1 phosphorylation was undetectable in
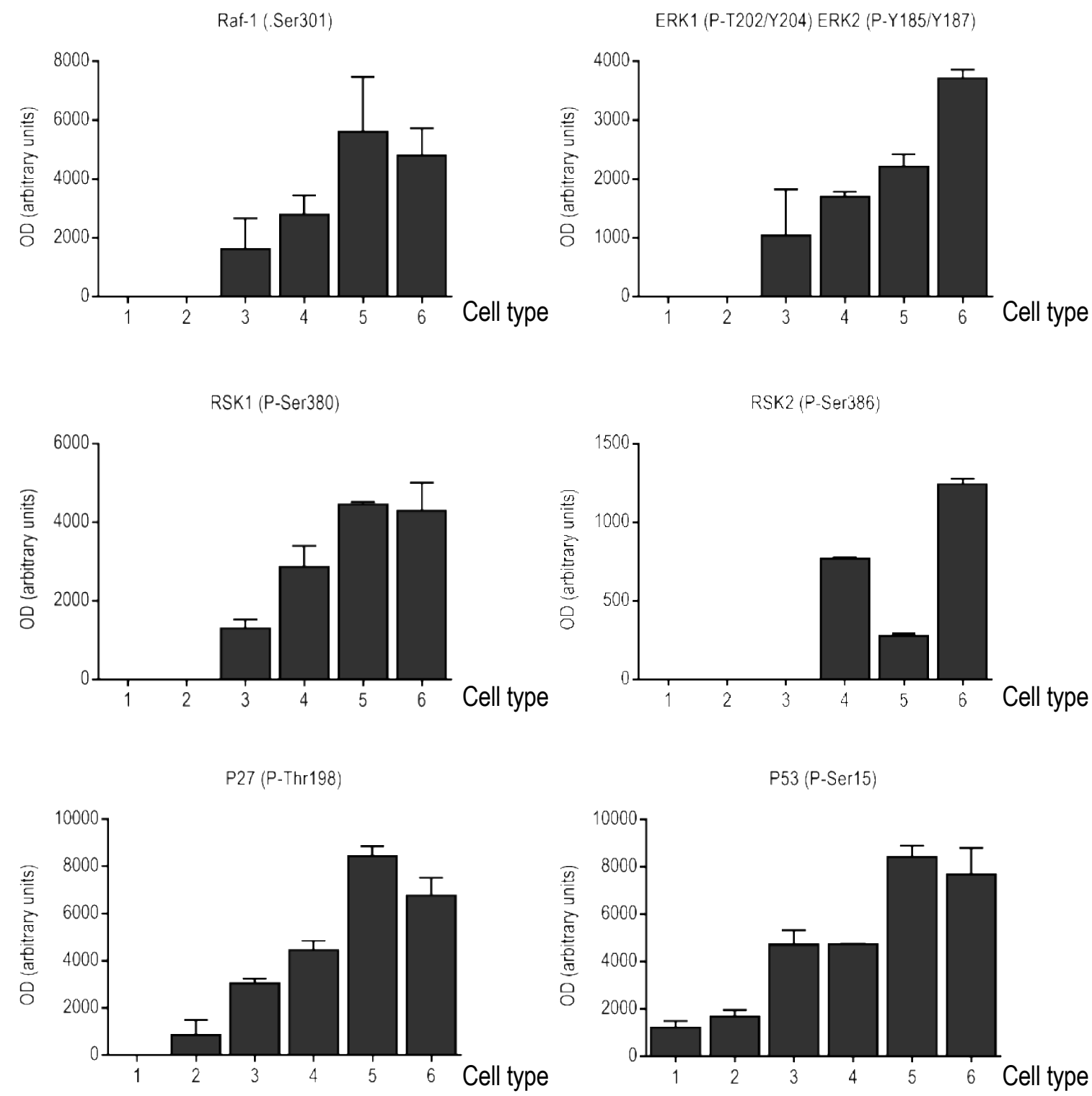

Figure 6. Transformation of immortalized NSC is associated with an increase in the activation of the ERK signalling pathway. Primary (cell type 1), LP-immortalized NSC (cell type 2), HP-immortalized NSC (cell type 3), GBM-derived cells (cell type 4) or meta stasis-derived cells (cell types 5 and 6) were culture d and the phosphorylation levels of proteins of the Ras-Raf-ERKpathway (Raf-1, ERK1, RSK1, RSK2), p27 and p53 were investigated. A progressive increase in the activation of the pathway, was observed throughout the process, with the highest lowest phosphorylation levels found in primary or LP cells (cell type 1 and 2, respectively) and the highest levels in cells obtained from heterotopic tumours (cell types 5 and 6).

either primary or LP-immortalized cells, but progressively increased in the other cell types, with the highest phosphorylation levels detected in cells from heterotopic tumours. In the case of RSK2 no phosphorylation was detected in primary, LP-immortalized, and HP-immortalized cells, and phosphorylation levels were also unexpectedly low in cells from heterotopic tumours originated from HP-immortalized NSC. Interestingly, although, both RSK1 and RSK2 are associated with glioma malignity, RSK1 has been described as a potential progression marker and a therapeutic target for gliomas. In fact, RSK1 phosphorylation levels (Ser380), which more specifically reveals ERK activation, are higher in GBM [24]. Additionally, RSK1 phosphorylates p27 at Thr198, leading to accumulation of phosphorylated p27 in the cytoplasm [25]. Accordingly, p27 levels progressively 
increased with a similar pattern to that observed in RSK-1. These findings, together with the increased levels of p53 detected, may suggest that, as we previously shown [26], increased cell proliferation (and, eventually, cell transformation) may occur despite the existence of a normal activation of the cellular checkpoints involved in the induction of senescence. Surprisingly, a so clear pattern of activation was not observed when other signalling pathways were investigating. This is the case of the phosphatidylinositol 3-kinase (PI3K)-Akt pathw ay that is activated in almost $90 \%$ of all GBM [2729]. However, we were unable to find any difference in the phosphorylation level of the leading members of this pathway, including PI3K, Akt, phosphatase and tensin homolog (PTEN) or mammalian Target of rapamycin (mTOR) (Suppl Fig. 1), among the different cells types. Overall, these results indicate that immortalization of NSC may be associated with a progressive activation of the Ras/Raf/ERK signalling pathway.

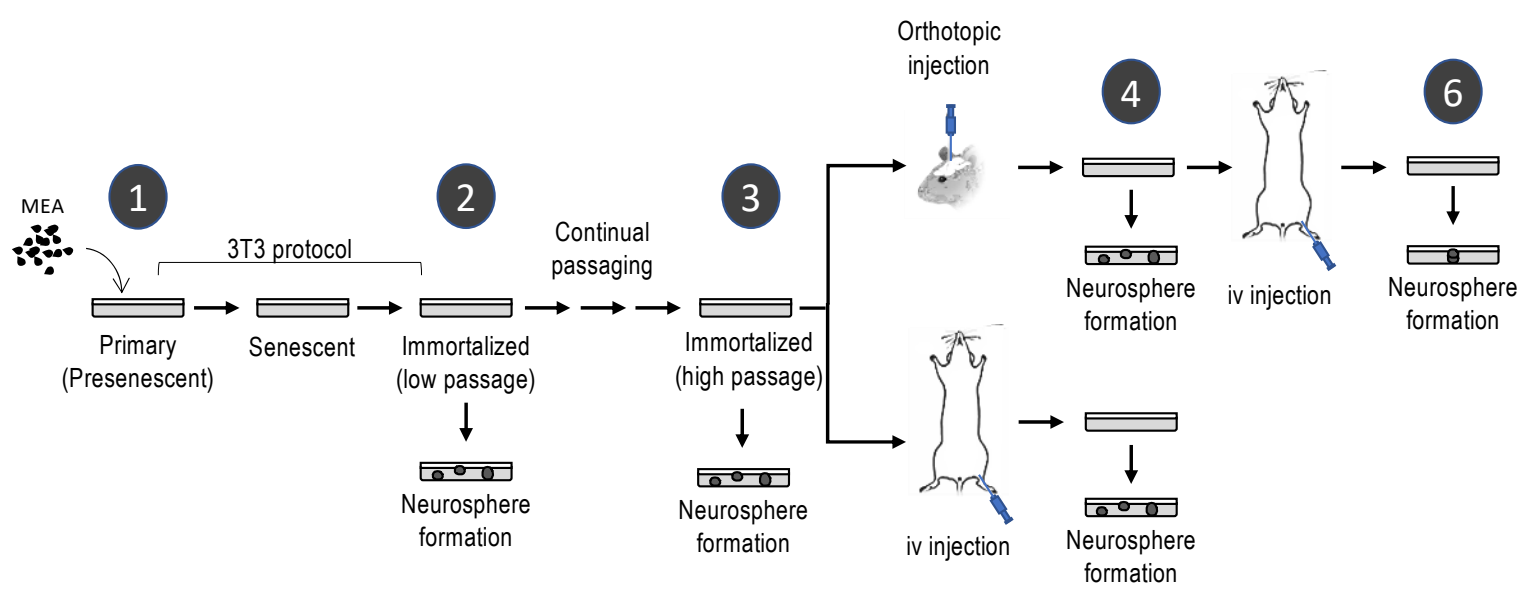

Figure 7. Experimental design used for the generation of the differentcell types investigated. Primary cultures of MEA obtained from $13.5 \mathrm{dpc}$ mouse embryos (1) were submitted to a $3 \mathrm{~T} 3$ protocol, resulting in the generation of immortalize d NSC (low passage) (2). Immortalized NSC can proliferate indefinitely, le ading to HP-immortalized NSC (3). Orthotopic injection of HP-immortalized NSC in mice results in the generation of GBM (4); while iv injection of HP-immortalized NSC results in the formation of heterotopic (metastatic) tumours (5). Finally, formation of heterotopic (metastatic) tumours is also observed after iv injection of GBM-derived cells (6). As indicated in the figure, the capacity to form neurospheres was assessed in every cell type.

\section{Discussion}

In the present study, we have demonstrated that continual passaging of immortalized NSC results in their transformation into cells that are able to produce either GBM or heterotopic tumours, when injected in adult mice. Although further studies are still necessary, our results support a role for NSC in the pathogenesis of GBM, at least for primary GBM, which accounts for more than $90 \%$ of this type of tumours [1]. This proposal is in keeping with other studies indicating that NSC may be the cells from which GBM originate, due to their self-renew al and proliferative capacities, and the relevance of the accumulation of somatic mutations in the process of gliomagenesis [29-31].

The role of embryonic stem cells on cancer has been largely debated. Cancer initiating cells or cancer stem cells (CSC) are a subpopulation of cells that has the driving force of carcinogenesis [30, 31] that can be identified in most ty pes of human cancer [32-35]. Although not all CSC are originated from embryonic cells, specific criteria to define CSC include (1) the ability to self-renew; (2) the capacity to differentiate into different lineages (multipotency); and (3) the ability to initiate tumours in animal models, which recapitulate the original disease phenotype and heterogenicity [36-39]. All these criteria are fulfilled by the HP-immortalized NSC used in this study and, therefore, they can be 
considered as truly CSC, thus supporting the hypothesis of NSC as the source of GBM. In this regard, it has been recently demonstrated that astrocyte-like NSC in the SVZ are the cell of origin that contains the driver mutations of human GBM [40]. Furthermore, astrocyte-like NSC that carry driver mutations migrate from the SVZ and lead to the development of high-grade malignant gliomas in distant brain regions [40].

Of special interest is the fact that no "external" hit is needed to induce the malignant transformation of NSC, other than their continuous passaging and the stress induced to overcome replicative senescence [19]. In fact, in contrast with the results reported in MEF placed on a 3T3 protocol, in which immortal cells emerge at low frequency [10], we were able to generate immortal NSC with a $100 \%$ frequency, and all HP-immortalized NSC were able to generate GBM when orthotopically injected in mice. Therefore, it is tempting to speculate that the mechanisms that allow primary cells to escape from replicative senescence are those leading to malignant transformation. In this context, it is interesting to note that those NSC that can overcome replicative senescence show increased activation of both p27 and p53 [19, and the present work]. This result, together with the early occurrence of hyperploidy in immortalized NSC may suggest the existence of an uncoupled response to the activation of the DNA damage response (DDR). Interestingly, similar results have been previously reported by our group in response to oncogene-induced senescence (OIS) in primary MEA [26]. In these cells, activation of Ras and elimination of RB does not induce cellular senescence, despite the activation of the cellular checkpoints related to DDR. It must be emphasized that MEA are the cells that give rise to immortal NSC after overcoming replicative senescence [9, 19 and the present study]. Therefore, the ability of MEA to escape cellular senescence, either replicative or OIS, could underlie an important role in gliomagenesis.

Although we do not presently know the mechanisms underlying this defective response, it is interesting to notice that the transition from primary to immortalized cells is associated with an almost total loss of euploid cells. Aneuploidy is one of the hallmarks of most human cancers, with around $90 \%$ of all solid tumours being aneuploid, mostly hyperdiploid [41-43]. Although both the mechanisms leading to aneuploidy and their consequences on tumorigenesis are still controversial, it has been proposed that tumour cells with significantly elevated genomic content (polyploid t umour cells) facilitate rapid tumour evolution. Furthermore, aneuploidy has been shown to precede transformation in a variety of cancers [44-47], and it has been proposed a role of aneuploidy during tumour initiation [16, 17]. In keeping with this, severe polyploidy was also an early event in the natural history of the transformation process described in the study, so it can be hypothesized that it may be involved in the appearance of the other biochemical and phenotypical changes observed, including the increased activation of ERK signalling $[48,49]$.

It remains to be elucidated whether similar mechanisms may account for the oncogenic transformation of NSC in vivo. Under physiological conditions, NSC are regulated by the orchestration of intrinsic and extrinsic signals that provide the complex regulatory architectures present in the neurogenic niche. The special microenvironment defined within the neurogenic niche permits the maintenance of the NSC pool and prevents terminal differentiation, thus allowing the balance between cell loss and cell replacement in the central nervous system [50-52]. Under our experimental conditions, cells are grown in the presence of FBS and, therefore, exposed, for a long time, to a wealth of grow th factors that are not present within the neurogenic niche. Therefore, it is tempting to speculate that disturbance of the microenvironment within the neurogenic niche may result in a dysregulated proliferation of NSC that, eventually, may cause the appearance of a GBM. In this respect, it has been shown that NSC niches of the human brain may be a mutational source for brain somatic mutations [42].

Another interesting conclusion of our study is the capacity of immortalized NSC to disseminate and form heterotopic tumours when injected in mice. Extracranial/extraspinal metastasis is a very uncommon entity in GBM, and only a low number of patients develop extracranial metastasis [11- 
14]. Although historically, GBM were not believed to metastasize because of the presence of the blood-brain barrier, improvements in the treatment of primary GBM has led to an increased in reported metastasis, mostly in the lungs, but also in other organs such as lymphatic nodes, bone, or liver [11-14]. In keeping with this, we found that lungs were the organs that more frequently presented heterotopic tumours (macroscopic and microscopic), but a widespread hematogenic dissemination was observed. This capacity for hematogenic dissemination is in concordance with recent studies demonstrating the existence of circulating tumour cells in the blood of $20 \%-39 \%$ of patients with GBM $[53,54]$. Since occurrence of extracranial/extraspinal metastasis is expected to increase as GBM treatment becomes more efficient, our results support the validity of our model to mimic in vitro the natural course of the disease in vivo. It is also quite remarkable that HPimmortalized NSC, have the same capacity to be highly metastatic than cells obtained from primary GBM. This indicates that metastatic genotype is acquired early in tumour progression as has been already proposed $[55,56]$.

In summary, we have developed an experimental model that allows to recapitulate the process of transformation of mouse embryo NSC into GBM-producing cells in vitro. Since most of the cells enter in senescence when submitted to the 3T3 protocol [19 and the present study], we do not presently know whether those cells that are able to overcome senescence, are the NSC present in the culture or just a fraction of them. In other words, it remains to be elucidated whether all NSC have the capacity of immortalization, or just some of them, as a consequence of a transformation process. In any case, we have found that the transformation process occurs with a $100 \%$ frequency, thus suggesting that oncogenic transformation is the unavoidable fate for, at least, a population of NSC, when undergoing long-term proliferation in vitro. Furthermore, the transformation likely occurs because of the presence of serum factors in the culture medium, thus highlighting theimportance of maintaining the NSC in an adequate environment. While remains to be elucidated whether a similar mechanism may be involved in the pathogenesis of GBM in vivo, a warning should be made about the transplantation of NSC as a tool for neural repair [51].

Finally, we also describe a novel model of gliomagenesis that recapitulates in vitro the transformation of primary MEA into cells that are able to generate both GBM and heterotopic tumours in vivo. This model has two important advantages over current systems. First, it can be used to recapitulate the pathogenesis of GBM and, therefore, to elucidate the timeline of the mutations that accounts for the generation of GBM. Second, it provides with a valuable tool to test the effectiveness of therapeutics at different times throughout the natural history of the disease. This characteristic w ould help to the development of personalized treatment strategies by tailoring drug effectiveness with mutational profiles. Finally, given the ability of all cell types (including those derived from GBM or heterotopic tumours) to form neurospheres when placed on LBE conditions, they can be used to generate $3 \mathrm{D}$ organoid culture systems $[57,58]$ to capture the phenoty pic and molecular particularities of GBM, as we have recently shown [59].

\section{Materials and Methods}

\subsection{Cell cultures}

Immortalized NSC were generated from $13.5 \mathrm{dpc}$ (day post coitum) C57BL/6 mice embryos, as previously described $[19,26]$. Briefly, pregnant C57BL/6 mice were sacrificed at $13.5 \mathrm{dpc}$ and uterine horns were then dissected. Each embryo was separated from its placenta and embryonic sac and transferred to an individual petri dish with Dulbecco's modified Eagle's medium (DMEM, SigmaAldrich, Madrid, Spain). The head of each embryo was individually transferred to fresh petri dishes, and brains were then isolated, finely minced, and dissociated by mechanical shearing, followed by filtration through a 40-micron mesh. Cells were plated in Falcon polystyrene culture dishes (BD Biosciences, Madrid, Spain) and grown in DMEM supplemented with $10 \%$ foetal bovine serum (Thermo Fisher Scientific, Madrid, Spain), $2 \mathrm{mM}$ glutamine, $2.5 \mathrm{U} / \mathrm{mL}$ penicillin, and $2.5 \mathrm{mg} / \mathrm{mL}$ 
streptomycin (all from Thermo Fisher Scientific). Cultures were maintained at $37^{\circ} \mathrm{C}$ in a humidified atmosphere of $5 \% \mathrm{CO}_{2}$. This method has been proved to consistently yield more than $95 \%$ of GFAP+ primary mouse embryo astrocytes (MEA) $[9,19,26]$. Immortalization of primary MEA w as achieved by using the 3T3 protocol [10], with appropriate modifications [19]. Cells were transferred to new dishes with fresh medium every 3 days, with the same cell density $\left(3 \cdot 10^{3} / \mathrm{cm}^{2}\right)$ seeded in every transfer. Continual cell passaging was used to generate long-term cultures of low passage (LP)immortalized cells (below 20 passages) or high passage (HP)-immortalized cells (40-100 passages) (see Fig. 1 for further details). Both the immortalization protocol and the long-term maintenance of immortalized cells were carried out in DMEM. Formation of neurospheres was induced by using a modification of the neurosphere assay $[9,60]$. In this case, cells growing in DMEM, were trypsinized and transferred to fresh polystyrene culture dishes (approximately $3 \times 105 / \mathrm{dish}$ ) with semi-synthetic (neurobasal) medium supplemented with $100 \mathrm{U} / \mathrm{mL}$ penicillin, $100 \mu \mathrm{g} / \mathrm{mL}$ st reptomycin, $1 \%$ Gibco B27 supplement, $10 \mathrm{ng} / \mathrm{mL} \mathrm{bFGF}$, and $10 \mathrm{ng} / \mathrm{mL}$ EGF (NBE conditions) [61]. Since immortalization occurred with a 100\% frequency, and no differences were observed in the outcome of the cells, results obtained with different batches of immortalized NSC are presented throughout this study.

To ensure the detection of the immortalized cells after injection in mice, and to rule out a spontaneous origin of the generated tumours, luminescence and fluorescence reporter systems were developed. To create the luminescence reporter, the pBABE-puro-Luc vector was transfected into Phoenix ecotropic retroviral packaging cells (a gift from C. Watzl) [62] by using JetPEI poly plus transfection system (Illkirch, France). Retroviruses-containing supernatant was collected 48 hours after transfection and used to infect immortalized cell cultures, using polybrene $(5 \mu \mathrm{g} / \mathrm{mL})$ as transduction enhancer. Cells were then selected for 48 hours with $2.5 \mu \mathrm{g} / \mathrm{mL}$ puromycin, and infection efficiency was measured by quantifying the luciferase activity using an optical in vivo imaging system (IVIS Spectrum, Perkin-Elmer, Waltham, MA). A red fluorescence reporter gene was created by replacing the sequence coding for GFP in a pMSCV PIG vector (Puro IRES GFP empty vector) with the sequence encoding the monomeric far-red fluorescent protein TagFP635 from a pTagFP635-C vector. The new vector was transfected into Phoenix ecotropic retroviral packaging cells and the supernatant was used to infect immortalized cells, as indicated before.

\subsection{Generation of orthotopic tumours}

Orthotopic tumours were generated by stereotaxic injection of immortalized NSC. Six-week-old C57BL/6 male mice were anesthetized by intraperitoneal injection of a ketamine $(80-100 \mathrm{mg} / \mathrm{kg})$ and xylazine (16-20 mg/kg) mixture and returned to a holding cage briefly before being placed on a stereotaxic frame (David Kopf Instruments, Tujunga, CA). The surgical area was carefully scrubbed, and a sagittal incision was made through the scalp. The periosteum was then retracted by gently rubbing and microinjections were made in the brain parenchyma according to a topographical map [63] (coordinates: anterior $-0.2 \mathrm{~mm}$, lateral $1 \mathrm{~mm}$ from bregma and depth $2.2 \mathrm{~mm}$ from the skull surface) by using a 25-gauge needle (Hamilton 7001 syringe, Hamilton Company, Reno, Nevada). The needle w as gently inserted into the skull opening, retracted to accommodate the injection volume $(5 \mu \mathrm{L})$ and the cell suspension $\left(1 \times 10^{5}\right.$ cells) w as slowly injected. Once the micro syringe removed, the head skin was sutured with surgical silk. Mice were monitored for anaesthetic recovery and postsurgical pain. To obtain GBM-derived cell cultures, tumours were finely minced and dissociated by mechanical shearing as indicated above. Cell cultures were grown in DMEM as described and neurosphere generation was induced by placing the cells in NBE conditions.

\subsection{Generation of heterotopic (metastatic) tumours}

To investigate the hematogenous dissemination of either HP-immortalized cells or GBM-derived cells, 3-week-old male mice were anesthetized with isoflurane $(3 \% \mathrm{v} / \mathrm{v})$, placed in a restrainer and injected with the corresponding cell suspension ( $3 \times 10^{5}$ cells diluted in $500 \mu \mathrm{L}$ of saline solution). Cells were injected in the caudal vein with a 25-gauge needle, and animals were monitored for 5-10 minutes 
to ensure haemostasis. Cell cultures from macroscopic metastatic lung tumours were performed as described. After carefully dissenting the tumours from the surrounding tissue, they were finely minced and dissociated by mechanical shearing. Cell cultures were grown in DMEM and neurosphere generation was induced by placing the cells in NBE conditions.

In order to test the presence of micrometastasis in several organs, cell cultures from lung, kidney, spleen, brain, bone marrow, testicles and liver were performed. Except for bone marrow, tissues were finely minced and dissociated as described. Form bone marrow cultures, femora and tibiae of the mice were harvested and flushed using phosphate-buffered saline(PBS) in a 1-ml syringe with a 25gauge needle. Cells were collected by centrifugation and seeded. In all cases, cultures were grow $n$ in DMEM and neurosphere generation was induced by placing the cells in NBE conditions.

\subsection{In vivo imaging}

For in vivo monitoring of tumoral grow th, luciferin w as injected intraperitoneally at a dose of $10 \mu \mathrm{l} / \mathrm{g}$ body weight. Mice were then anesthetized with isoflurane $(3 \% \mathrm{v} / \mathrm{v})$ and placed on the imaging stage of an optical imaging system (IVIS Spectrum). Images were collected every minute from 15 to $30 \mathrm{~min}$ after luciferin injection, and photon emission was quantified using Living Image Software (Living Image 3.1, PerkinElmer).

\subsection{Immunocytochemistry}

For immunocytochemical analysis, approximately $5 \times 10^{3}$ cells w ere seeded in glass coverslips, placed in 24-multiwell plates, and incubated for $24 \mathrm{~h}$, as described above. Cells were then fixed in $96 \%$ ethanol for $1 \mathrm{~h}$, rinsed in PBS, and permeabilized by adding $250 \mu \mathrm{L}$ of $0.1 \%$ TritonX-100, $0.3 \%$ bovine serum albumin (BSA) for $1 \mathrm{~h}$. After rinsing the cells three times in PBS, an overnight incubation at $4^{\circ} \mathrm{C}$ w as performed $w i t h$ the following primary antibodies: anti-glial fibrillary acidic protein (GFAP) (Dako, Agilent Technologies, Madrid, Spain; ready to use), anti-myelin basic protein (MBP) (Dako, Agilent Technologies; dilution 1:2000), anti-nestin (Merk Millipore, Madrid, Spain; dilution 1:200), anti RFP ( $($ IIIT, Dako, Agilent Technologies; dilution 1:2000), and anti-Ki67 (Seven Hills Bioreagents, Cincinnati, OH, USA; dilution1:1000). Positive cells were detected with a univers al second antibody kit that uses a peroxidase-conjugated labelled dextranpolymer (EnvisionPlus, Dako, Agilent Technologies, Santa Clara, CA, USA) and photographed with an Olympus BX43 camera (Olympus Optical Co., Tokyo, Japan).

\subsection{Immunohistochemistry}

For histological evaluation, tissues were fixed by immersion in $10 \%$ buffered formalin for $24 \mathrm{~h}$, then dehydrated in ethanol (70\%) for $24 \mathrm{~h}$, and embedded in paraffin using a standard procedure. Serial $4-\mu \mathrm{m}$ sections were consecutively cut with a microtome (Leica Microsystems GmbH, Wetzlar, Germany) and transferred to adhesive-coated slides. Immunohistochemistry w as performed with a universal second antibody kit that uses a peroxidase-conjugated labelled-dextran polymer (Envision Plus, Dako, Denmark). The following primary antibodies w ere used: anti-glial fib rillary acidic protein (GFAP) (Dako, Agilent Technologies, Madrid, Spain; ready to use), anti-myelin basic protein (MBP) (Dako, Agilent Technologies; dilution 1:2000), anti-nestin (Merk Millipore, Madrid, Spain; dilution 1:200), anti RFP (Dako, Agilent Technologies; dilution 1:2000), and anti-Ki67 (Seven Hills Bioreagents, Cincinnati, OH, USA; dilution1:1000). Overnight incubation at $4^{\circ} \mathrm{C}$ was performed with every antibody. For negative controls, each staining run was incubated with normal rabbit serum instead of the primary antibody. Counterstaining w as performed with hematoxylin-eosin (H\&E) staining.

\subsection{Real time $P C R$}


Total RNA was isolated from the different cell cultures by using TRIzol (Invitrogen). cDNA was synthesized with the Transcriptor first strand cDNA synthesis kit (Roche Diagnostics, Basel, Switzerland), and real-time PCR w as performed using SYBR Green Master Mix (Applied Biosystems, Foster City, CA) with an iCycler equipment (7500 PCR Systems, Applied Biosystems). Samples were denatured at $95^{\circ} \mathrm{C}$ for $15 \mathrm{sec}$, annealed at $55 \mathrm{sec}$, for $15 \mathrm{sec}$ and extended at $72^{\circ} \mathrm{C}$ for $40 \mathrm{sec}$, for a total of 40 cycles. The Sequence detection software1.4 (Applied Biosystems) was used for quantification, using GAPDH as control. The oligonucleotide sequences used are: GAPDH forward: AGGTCGGTGAACGGATTTG; GAPDH reverse: GGGGTCGTTGATGGCAACA; GFAP forward: TCGCTTTCCTCTGAACGCTTCTCG; GFAP reverse: TCTGAACGCTGTGACTTGGAGTTCC; MBP forward: CCAAGTTCACCCCTACTCCA; MBP reverse: AGGGGGAAGAAAACAAAGGA; nestin forward: CCCTGAAGTCGAGGAGCTG; nestin reverse: CTGCTGCACCTCTAAGCGA. Statistical analysis w as performed with the nonparametric test of Kolmogorov-Smirnov. Statistical significance was established at $\mathrm{p}<0.05$.

\subsection{Metaphase chromosome preparation}

Metaphase spreads were prepared after treating the cells with colcemid (Sigma-Aldrich, $0.1 \mu \mathrm{g} / \mathrm{mL}$ ) for $7 \mathrm{hr}$. Cells were then incubated in hypotonic buffer $(0.05 \mathrm{M} \mathrm{KCl}, 0.0034 \mathrm{M}$ trisodium citrate) for $20 \mathrm{~min}$ at $37^{\circ} \mathrm{C}$ and fixed in $75 \%$ methanol, $25 \%$ acetic acid. Cells were then spotted onto microscope slides and stained with $2 \%$ Wright stain (Sigma-Aldrich, $0.1 \mu \mathrm{g} / \mathrm{mL}$ ) in Gurr buffer, $\mathrm{pH} 7.0$ (Invitrogen). Metaphase chromosomes were scored using a Leica 2005 microscope under a 100X oil objectivelens. At least 50 metaphases were analysed from three independent experiments.

\subsection{Cell proliferation assay}

Cells were seeded at $10 \times 10^{3}$ (primary), $5 \times 10^{3}$ (immortalized low passage) or 2,5x103 (immortalized high passage, GBM-derived and metastasis-derived) and grown in DMEM for 1, 3, 5 or 7 days. At these times, cells were fixed and stained with $0.1 \%$ violet crystal (Sigma) for 30 minutes and then washed with PBS to remove the dye excess. Dye content was quantified in a spectrophotometer. To determine the rate of BrdU incorporation, $10^{6}$ cells were seeded in poly-L-lysine-coated slides (1 $\mathrm{mL} / \mathrm{slide})$ and maintained for $24 \mathrm{~h}$. Cells were grown in the presence of $\mathrm{BrdU}(10 \mathrm{mM}$, Sigma -Aldrich) for $2.5 \mathrm{~h}$, and BrdU+ cells were detected by immunocytochemistry using a monoclonal antibody (BD Biosciences, dilution 1:2000). Representative images were captured with an Olympus DP72 camera (Olympus Optical Co., Tokyo, Japan), and the number of BrdU+ cells was quantified in 10 random fields per slide.

\subsection{Dot blot assay}

A multiplexed protein detection kit (C-Series Human/Mouse AKT Pathway Phosphorylation Array C1, RayBiotech, Norcross, GA) was used to investigate the existence of changes in the signalling machinery among the different cell ty pes generated. All procedures were performed according to the manufacturer's instructions Briefly, cells were washed with ice-cold PBS and solubilized in lysis buffer. Cell lysates were then centrifuged $\left(14,000 \mathrm{rpm}, 5\right.$ minutes, $\left.4{ }^{\circ} \mathrm{C}\right)$ and protein concentration was determined using the Bradford assay (Bio-Rad Laboratories). Membranes were blocked for 30 min at room temperature and incubated overnight at $4^{\circ} \mathrm{C}$ with $200 \mu \mathrm{g}$ of each sample, before incubation with the detection antibody cocktail ( $2 \mathrm{~h}$ at room temperature). Immunoreactivity was detected by chemiluminescence using X-ray film (Fuji Medical, Japan) to visualize the dots. Images were analysed with the ImageJ open source image software (https://imagej.nih.gov/ij/). Data were corrected for thelocal background and normalized for positive and negativeinternal controls.

\subsection{Study approval}


All animal procedures were approved and performed according to the guidelines set out by the Institutional Ethics Committee for Animal Experimentation (protocol No 15005AE/07/FUN01/FIS02/JACP1).

Supplementary Materials: Supplementary materials can be found at www.mdpi.com/xxx/s1. Figure S1

Author Contributions: Conceptualization, Cristina Almengló, José A. Costoya and Víctor M. Arce; Data curation, Cristina Almengló, Máximo Fraga, Jesús Devesa, José A. Costoya and Víctor M. Arce; Formal analysis, Cristina Almengló, Jesús Devesa, José A. Costoya and Víctor M. Arce; Funding acquisition, José A. Costoya and Víctor M. Arce; Investigation, Cris tina Almengló, Pilar Caamaño, Máximo Fraga, Jesús Devesa, José A. Costoya and Víctor M. Arce; Methodology, Cristina Almengló, Pilar Ca amaño and Máximo Fraga; Project administration, José A. Costoya and Víctor M. Arce; Supe rvision, Jesús Devesa, José A. Cos toya and Víctor M. Arce; Validation, Cristina Almengló, Pilar Ca amaño and Máximo Fraga; Writing - original draft, Víctor M. Arce; Writing - re view \& editing, Cristina Almengló, Jesús Devesa, José A. Costoya and Víctor M. Arce.

Funding: This study was supported in part by Xunta de Galicia (2014-PG029), University of Santiago de Compostela (2018-PU001), Ministerio de Economía y Competitividad (PI15/01129, J.A.C.), the Centro Singular de Investigación de Galicia accreditation 2016-2019, ED431G/05), and the European Regional Development Fund (ERDF).

Acknowledgments: We acknowledge C. Watzl (Institute for Immunology, University Heidelberg) for providing us with the Phoenix-Eco packaging cells. The expert technical help of Ana Senra is also greatly acknowle dged.

Conflicts of Interest: The authors declare no conflict of interest. The founding sponsors had no role in the design of the study; in the collection, analyses, or interpretation of data; in the writing of the manuscript, and in the decision to publish the results.

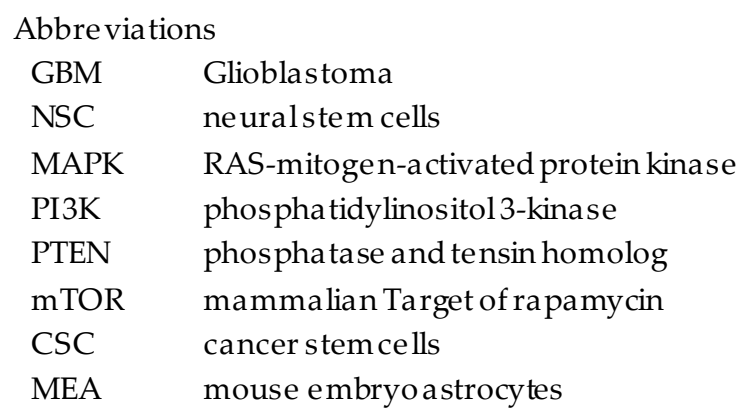

\section{References}

1. Joshi, S.K.; Lucic, N.; Zuniga, R. Molecular pathogenesis of glioblastoma multiforme: Nuances, obstacles, and implications for trea tment. World. J. Neurol. 2015, 5, 88-101

2. Louis, D.; Perry, A.; Reifenberger, G.; von Deimling, A.; Figarella-Branger, D.; Cavenee, W.K.; Ohgaki, H.; Wiestler, O.D.; Kleihues, P.; Ellison, D.W. The 2016 World Health Organization classification of tumors of the central nervous system: a summary. Acta Neuropathol. 2016, 131, 803-820

3. Ostrom, Q.T.; Gittleman, H.; Truitt, G.; Boscia, A.; Kruchko, C.; Barnholtz- Sloan, J.S. CBTRUS statistical report: Primary brain and other central nervous system tumors diagnosed in the United States in 20112015. Neuro-oncol. 2018, 20, iv1-iv86

4. Patel, A.P.; Tirosh, I.; Trombetta, J.J.; Shalek, A.K.; Gille spie, S.M.; Wakimoto, H.; Cahill, D.P.; Nahed, B.V.; Curry, W.T.; Martuza, R.L., et al. Single-cell RNA-seq highlights intratumoral heterogeneity in primary glioblastoma. Science 2014,344,1396-1401

5. Jacob, F.; Salinas, R.D.; Zhang, D.Y.; Nguyen, P.T.T.; Schnoll, J.G.; Wong, S.Z.H.; Thokala, R.; Sheikh, S.; Saxena, D.; Prokop, S., et al. A patient-derived glioblastoma organoid model and biobank recapitulates inter- and intra-tumoral he terogeneity. Cell 2020, 180, 188-204

6. Xie, Y., Bergström, T., Jiang, Y., Johansson, P., Marinescu, V.D., Lindberg, N., Segerman, A., Wicher, G., Niklasson, M., Baskaran, S., et al. The human glioblastoma cell culture resource: Validated cell models representing all mole cular subtypes. EBioMedicine 2015, 2,1351-1363

7. Caragher, S.; Chalmers, A.J.; Gomez-Roman, N. Glioblastoma's next top model: Novel culture systems for brain cancer radiotherapy research. Cancers (Basel) 2019, 11, 44 
8. Allen, M.; Bjerke, M.; Edlund, H.; Nelander, S.; We stermark, B. Origin of the U87MG glioma cell line: Good news and bad news. Sci. Transl. Med. 2016, 8, 354re 353

9. Almengló, C.; Devesa, P.; Devesa, J.; Arce, V.M. GPE promotes the proliferation and migration of mouse embryonic neural stem cells and their progeny in vitro. Int. J. Mol. Sci. 2017, 18, 1280

10. Todaro, G.J.; Green, H. Quantitative studies of the growth of mouse embryo cells in culture and their development into established lines. J. Cell. Biol. 1963 17, 299-313

11. Goodwin, C.R., Liang, L., Abu-Bonsrah, N., Hdeib, A., Elder, B.D., Kosztowski, T., Bettegowda, C., La terra, J., Burger, P., Sciubba, DM. Extraneural glioblastoma multiforme vertebral metastasis. World Neurosurg. 2016, 89, 578-582

12. Taskapilioglu, M.O., Aktas, U., Eser, P., Tolunay, S., Bekar A. Multiple extracranial metastases from secondary glioblastoma: a case re port and review of the literature. Turk. Neurosurg. 2013, 23, 824-827

13. Awan, M.J., Liu, S.K., Sahgal, A., Das, S., Chao, S.T., Chang, E.L., Knisely, J., Redmond, K., Sohn, J.W., Machtay, M., et al. Extra-CNS metastasis from glioblastoma: A rare clinical entity. Expert. Rev. Anticancer Ther. 2015, 15, 545-52

14. Hoffman, H.A.; Li, C.H.; Everson, R.G.; Strunck, J.L.; Yong, W.H.; Lu D. Primary lung metastasis of glioblastoma multiforme with e pidural spinal metastasis: Case re port. J. Clin. Neurosci. 2017, 41,97-99

15. Seoane, J.; De Mattos-Arruda, L. Escaping out of the brain. Cancer Discov. 2014, 4, 1259-1261

16. Li, R.; Yerganian, G.; Duesberg, P.; Kraemer, A.; Willer, A.; Rausch, C.; Hehlmann, R. Aneuploidy correlated $100 \%$ with chemical transformation of Chinese hamster cells. Proc. Natl. Acad. Sci. U.S.A. 1997, 94,14506-14511

17. Duesberg, P.; Rausch, C.; Rasnick, D.; Hehlmann, R. Genetic instability of cancer cells is proportional to their degree of aneuploidy. Proc. Natl. Acad. Sci. U.S.A. 1998, 95,13692-13710

18. Rasnick, D.; Duesberg, P. How aneuploidy affects metabolic control and causes cancer. Biochem. J. 1999, 340, 621-630

19. Almengló, C.; González-Mosquera, T.; Caamaño, P.; Seoane, M.; Fraga, M.; Deve sa, J.; Costoya, J.A.; Arce, V.M. Immortalization of a cell line with neural stem cell characteristics de rived from mouse e mbryo brain. Dev. Dyn. 2020, 249, 112-124

20. Lo, H.W. Targeting Ras-RAF-ERKand its interactive pa thways as a novel the rapy for malignant gliomas. Curr. Cancer Drug Targets 2010,10, 840-848

21. Mao, H.; Lebrun, D.G.; Yang, J.; Zhu, V.F.; Li, M. Deregulated signaling pathways in glioblastoma multiforme: molecular mechanisms and the rapeutic targets. Cancer Invest. 2012, 30, 48-56

22. Hannen, R.; Hauswald, M.; Bartsch, J.W. A rationale for targeting extracellular regulated kina ses ERK1 and ERK2 in glioblastoma. J. Neuropathol. Exp. Neurol. 2017, 76, 838-847

23. Romeo, Y.; Zhang, X.; Roux, PP. () Regulation and function of the RSK family of protein kinases. Biochem. J. 2012, 44, 553-569

24. Hajj, G.N.M.; da Silva, F.F.; de Bellis, B.; Lupinacci, F.C.S.; Bellato, H.M.; Cruz, J.R.; Segundo, C.N.C.; Faquini, I.V.; Torres, L.C.; Sanematsu, P.I.; et al. Aberrant expression of RSK1 characterizes high-grade gliomas with immune infiltration. Mol. Oncol. 2020, 14, 159-179

25. Larrea, M.D.; Hong, F.; Wander, S.A.; da Silva, T.G.; Helfman, D.; Lannigan, D.; Smith, J.A.; Slingerland, J.M. RSK1 drives p27Kip1 phosphorylation at T198 to promote RhoA inhibition and increa se cell motility. Proc. Natl. Acad. Sci. U.S.A. 2009, 106, 9268-9273

26. Seoane, M.; Costoya, J.A.; Arce, V.M. Uncoupling Oncogene-Induced Senescence (OIS) and DNA Da mage Response (DDR) triggered by DNA hyper-replication: lessons from primary mouse embryo astrocytes (MEA). Sci. Rep. 2017, 7,12991

27. Sami, A.; Karsy, M. Targeting the PI3K/AKT/mTOR signaling pathway in glioblastoma: novel the rapeutic agents and advances in understanding. Tumour Biol. 2013, 34, 1991-2002

28. Li, X.; Wu C.; Chen N.; Gu H; Yen A.; Cao L.; Wang E.; Wang L. PI3K/Akt/mTOR signaling pathway and targe ted the rapy for glioblastoma. Oncotarget 2016, 7, 33440-33450

29. Sanai, N.; Tramontin, A.; Quiñones-Hinojosa, A.; Barbaro, N.M.; Gupta, N.; Kunwar, S.; Lawton, M.T.; McDermott, M.W.; Parsa, A.T.; García Verdugo, J.M.; et al. Unique astrocyte ribbon in adult human brain contains neural stem cells but lacks chain migration. Nature 2004, 427, 740-744

30. Alcantara Llaguno, S.; Chen, J.; Kwon, C.-H.; Jackson, E.L.; Li, Y.; Burns, D.K.; Alva rez-Buylla, A.; Pa ra da, L.F. Malignant astrocytomas originate from neural stem/progenitor cells in a somatic tumor suppressor mouse model. Cancer Cell 2009, 15, 45-56 
31. Batlle, E.; Clevers, H. () Cancer stem cells revisited. Nat Med 2017, 23, 1124-1134

32. Tomasetti, C.; Li, L.; Vogelstein, B. Stem cell divisions; somatic mutations; cancer etiology; and cancer prevention. Science 2017, 355, 1330-1334

33. Chang, J.C. Cancer stem cells role in tumor growth; recurrence; metastasis; and treatment resistance. Medicine 2016, 95, S1(e4766)

34. Bonnet, D.; Dick, J.E. Human acute myeloid leukemia is organized as a hierarchy that originates from a primitive hematopoietic cell. Nat Med 1997, 3, 730-737

35. Smith, L.M.; Nesterova, A.; Ryan, M.C.; Duniho, S.; Jonas, M.; Anderson, M.; Zabinski, R.F.; Sutherland, M.K.; Gerber, H.P.; Van Orden, K.L. et al. CD133/prominin-1 is a potential the ra peutic target for antibodydrug conjugates in he pa tocellular and gastric cancers. Br. J. Cancer 2008, 99, 100-109

36. Takaish,i S.; Okumura, T.; Tu, S.; Wang, S.S.; Shibata, W.; Vigneshwaran, R.; Gordon, S.A.; Shimada, Y; Wang, T.C. Identification of gastric cancer stem cells using the cell surface marker CD44. Stem Cells 2009, 27, 1006-1020

37. Doherty, M.R.; Smigiel, J.M.; Junk, D.J.; Jackson, M.W. Cancer stem cell plasticity drives the rapeutic resistance. Cancers (Basel) 2016, 8, 8

38. Singh, S.K.; Hawkins, C.; Clarke, I.D.; Squire, J.A.; Bayani, J.; Hide, T.; Henkelman, R.M.; Cusimano, M.D.; Dirks, P.B. Identifica tion of human brain tumour initia ting cells. Nature 2004, 432, 396-401

39. Sawada, M.; Sawamoto, K. Mechanisms of neurogenesis in the normal and injured adult brain. Keio J. Med. 2013, 62, 13-28

40. Lee, J.H.; Lee, J.E.; Kahng, J.Y.; Kim S.H.; Park, J.S.; Yoon, S.J.; Um, J.-Y.; Kim, W.K.; Lee, J .-K.; Park, J. et al. Human glioblastoma arises from subventricular zone cells with low-level driver muta tions. Nature 2018, 560, 243-247

41. Duensing, A.; Duensing, S. Centrosomes; polyploidy and cancer. Adv. Exp. Med. Biol. 2010, 676, 93-103

42. Coward, J.; Harding, A. Size does matter: Why polyploid tumor cells a re critical drug targets in the war on cancer. Front. Oncol. 2014, 4, 123

43. Weaver, B.A.; Cleveland, D.W. The aneuploidy paradox in cell growth and tumorigenesis. Cancer Cell 2008, $14,431-433$

44. Dooley, T.P.; Mattern, V.L.; Moore, C.M.; Porter, P.A.; Robinson, E.S.; Vandeberg, J.L. Cell lines derived from ultra violet radia tion-induce d benign melanocy tic nevi in Monodelphis domestica exhibit cytogenetic aneuploidy. Cancer Genet. Cytogenet. 1993, 71, 55-66

45. Ried, T.; Heselmeyer-Haddad, K.; Blegen, H.; Schröck, E.; Auer, G. Genomic changes defining the genesis; progression; and malignancy potential in solid human tumors: a phenotype/genotype correlation. Genes Chromosomes Cancer 1999, 25, 195-204

46. Doak, S.H.; Jenkins, G.J.; Parry, E.M.; Griffiths, A.P.; Baxter, J.N.; Parry, J.M. Differential expre ssion of the MAD2; BUB1 and HSP27 genes in Barrett's oesophagus - their association with aneuploidy and neoplastic progression. Mutat. Res. 2004, 547, 133-144

47. Cardoso, J.; Molenaar, L.; De Menezes, R.X.; Van Leerdam, M.; Rosenberg, C.; Möslein, G.; Sampson, J.; Morreau, H.; Boer, J.M.; Fodde, R. Chromosomal instability in MYH-and APC-mutant adenomatous polyps. Cancer Res. 2006, 66, 2514-2519

48. Furgason, J.M.; Li, W .; Milholland, B.; Cross, E.; Li Y.; McPherson, C.M.; Warnick, R.E.; Rixe, O.; Sta mbrook, P.J.; Vijg, J.; Bahassi, E.M. Whole genome sequencing of glioblastoma multiforme identifies multiple structural variations involve din EGFR activation. Mutagenesis 2014, 29, 341-350

49. Jun, H.J.; Appleman, V.A.; Wu, H.; Rose, C.M.; Pineda, J.J.; Yeo, A.T.; Delcuze, B.; Lee, C.; Gyuris, A.; Zhu, H.; et al. A PDGFR $\alpha$-driven mouse model of glioblastoma reveals a stathmin1-mediated mechanism of sensitivity to vinblastine. Nat. Commun. 2018, 9, 3116

50. Gage, F.H. Mammalian ne ural stem cells. Science 2000, 287, 1433-1438

51. Arce, V.M.; Devesa, P.; Devesa, J. Role of growth hormone (GH) in the tre atment on neural dise ases: from neuroprotection to ne ural re pair. Neurosci. Res. 2013, 76,179-186

52. Vining, K.H.; Mooney, D.J. Mechanical forces direct stem cell behaviour in de velopment and regeneration Nat. Rev. Mol. Cell. Biol. 2017, 18, 728-742

53. Sullivan, JP; Nahed, BV; Madden, MW; Oliveira, SM; Springer, S; Bhere, D; Chi, AS; Wakimoto, H; Rothenberg, SM; Sequist, LV; et al. Brain tumor cells in circulation are enriched for mesenchymal gene expression. Cancer Discov. 2014, 4, 1299-309 
54. Lombard, A.; Goffart, N.; Rogister, B. Gliobla stoma circulating cells: reality trap or illusion? Stem Cells Int. 2015,182985

55. Bernards, R.; Weinberg, R.A. A progression puzzle. Nature 2002, 418, 823

56. Wouw, A.J.van de; Janssen-Heijnen, M.L.; Coebergh, J.W.; Hillen, HF Epidemiology of unknown primary tumours; incidence and population-based survival of 1285 patients in Southeast Netherlands; 1984-1992. Eur. J. Cancer 2002, 38, 409-413

57. Kadoshima, T.; Sakaguchi, H.; Nakano, T.; Soen, M.; Ando, S.; Eiraku, M.; Sa sai, Y. Self-organization of axial pola rity; inside-out layer pattern; and species-specific progenitor dynamics in human ES cell-de rived neocortex. Proc. Natl. Acad. Sci.U.S.A. 2013, 110, 20284-20289

58. Paşca, A.M.; Sloan, S.A.; Clarke, L.E.; Tian, Y.; Makinson, C.D.; Huber, N.; Kim, C.H.; Park, J.Y.; O’Rourke, N.A.; Nguyen, K.D.; et al. Functional cortical neurons and a strocytes from human pluripotent stem cells in 3D culture. Nat. Methods 2015, 12, 671-678

59. Gomez-Randulfe, I.; Golan, I.; Zumalave, J.A.; Pardo-Vazquez, J.L.; Arce, V.M.; Costoya, J.A. Organoids as an improved in vitro model of glioma. II Annual CIMUS Workshop 2019, p19

60. Azari, H.; Sharififar, S.; Rahman, M.; Ansari, S.; Reynolds, B.A. Establishing embryonic mouse neural stem cell culture using the neurosphere assay. J. Vis. Exp. 2011, 47, 2457

61. Lee, J.; Kotliarova, S.; Kotliarov, Y.; Li, A.; Su, Q.; Donin, N.M.; Pastorino, S.; Purow, B.W .; Christopher, N.; Zhang, W.; et al. Tumor stem cells derived from glioblastomas cultured in bFGF and EGF more closely mirror the phenoty pe and genotype of primary tumors than do serum-cultured cell lines. Cancer Cell 2006, 9, 391-403

62. Swift, S.; Lorens, J.B.; Acha coso, P.; Nolan, G.P. Ra pid production of retroviruses for efficient gene de livery to mamma lian cells using 293T cell-based systems. Curr. Protoc. Immunol. 200, 10, 10.17C

63. Paxinos, G.; Franklin, K.B.J. Paxinos and Franklin's the mouse brain in stereotaxic coordinate.5th edition. 2019. Aca demic Press. Cambridge, MA 